RESEARCh PAPER

\title{
Effect of cold pre-treatment on another culture in different Brassica genotypes
}

\section{PREETI KUMARI AND A.K. SINGH}

School of Biotechnology, Sher-e-Kashmir University of Agricultural Sciences and Technology (J) Chatha, JAMMU

(J.\&K.) INDIA

Stress is an essential component to enhance callus induction in anther culture. Cold pretreatment has been used in cereal crops but very seldom attempted in Brassica anther culture. In order to assess the effect of cold pretreatment $\left(4^{\circ} \mathrm{C}\right)$ of flower buds subjected to a liquid medium for 5, 10 and 12 days for callus induction in different genotypes of Brassica, three varieties (GSL1, DGS1 and RSPN25) of B. napus and three varieties of Brassica juncea (RSPR01, Varuna and Kranti) were evaluated. The appropriate duration of cold pre-treatment of flower buds was found to be 10 days which stimulated the maximum callus induction. Cold pretreatment was also able to promote development including the improvement of embryo quality and acceleration of embryogenesis.

Key words : Haploids, Brassica napus, Brassica juncea, Embryogenesis, Organogenesis

How to cite this paper : Kumari, Preeti and Singh, A.K. (2014). Effect of cold pre-treatment on anther culture in different Brassica genotypes. Asian J. Bio. Sci., 9 (2) : 156160 . 